\title{
CRIANÇAS INDÍGENAS GUARANI NHANDEWA NO NORTE DO PARANÁ: APRENDIZAGENS CULTURAIS E ESCOLARES
}

\author{
Marcella Hauanna Cassulla (UEM)* \\ Rosangela Celia Faustino (UFSC)**
}

\section{RESUMO}

A criança indígena, na organização sociocultural de cada povo, tem formas próprias de aprender, recebendo cuidados, orientação e atenção dos parentes. Na cultura Nhandewa, todos os espaços da aldeia são espaços de aprendizagem das crianças. Os mais velhos, os tudjás, assim como os Txamõi e as Djaryi, sabedores das tradições, as repassam às novas gerações em situações e espaços propícios, como a Oy Guatsu. Neste texto apresentamos e discutimos elementos da educação da criança Guarani Nhandewa, observados e registrados, especialmente, em suas vivências em eventos culturais, em terras indígenas do norte do Paraná. Evidenciou-se que os professores Nhandewa, com apoio de suas comunidades, têm buscado articular os conhecimentos escolares aos conhecimentos ancestrais, no espaço escolar e nos eventos culturais nas aldeias, configurados como momentos de significativas aprendizagens para as crianças Guarani.

Palavras-chave: Infância indígena. Criança Guarani Nhandewa. Sistemas educativos.

\section{ABSTRACT}

\section{GUARANI NHANDEWA INDIGENOUS CHILDREN IN NORTHERN PARANÁ: CULTURAL AND ACADEMICAL LEARNING}

The indigenous child, in the socio-cultural organization of each people, has own ways of learning receiving care, guidance and permanent attention from relatives. In the Nhandewa culture, all village spaces are children's learning spaces. The elders, the tudjás, the txamõi and the djaraí, knowing the traditions, pass it on to the new generations in auspicious situations and spaces, like $\mathrm{Oy}$ Guatsu. In this text we present and discuss elements of the education of the Guarani Nhandewa child observed and recorded, especially in their experiences in cultural events in indigenous lands in the north of Paraná. It was evidenced

* Mestre em Educação pela Universidade Estadual de Maringá (UEM). Professora da Educação Básica na Prefeitura Municipal de Maringá. E-mail: marcellacassula@hotmail.com

** Doutora em Educação pela Universidade Federal de Santa Catarina (UFSC). Professora do Departamento de Teoria e Prática da Educação da Universidade Estadual de Maringá (UEM). Coordenadora do Programa Saberes Indígenas na Escola (MEC/ SECADI) Núcleo UEM/PR. E-mail: rcfaustino@uem.br 
that Nhandewa teachers have sought to articulate the schoolastic knowledge with the ancestral knowledge, in the school space and in non-school spaces such as the cultural events in the villages, configured like moments of significant learning for the Guarani children.

Keywords: Indigenous childhood. Guarani Nhandewa child. Educational systems.

\section{RESUMEN}

\section{NIÑOS INDÍGENAS GUARANÍ NHANDEWA EN EL NORTE DE LA PROVINCIA DEL PARANÁ: APRENDIZAJES CULTURALES $Y$ ESCOLARES}

El niño indígena, en la organización sociocultural de cada pueblo, tiene formas propias de aprender con orientación y atención de los parientes. En la cultura Nhandewa, todos los espacios de la aldea son espacios de aprendizaje de los niños. Los más viejos, tudjás, los txamõi y las djaraí, sabedores de las tradiciones, las repasan a las nuevas generaciones en situaciones y espacios propicios, como la Oy Guatsu. En este texto presentamos y discutimos elementos de la educación del niño Guaraní Nhandewa, observados y registrados, especialmente, en sus vivencias en eventos culturales, en tierras indígenas del norte de la provincia de Paraná en Brasil. Se evidenció que los profesores Nhandewa, con apoyo de sus comunidades, han buscado articular los conocimientos escolares a los conocimientos ancestrales, en el espacio escolar y en los eventos culturales en las aldeas, siendo estos, momentos de gran aprendizajes para los niños Guaraní. Palabras clave: Infancia indígena. Niño Guaraní Nhandewa. Sistemas educativos.

\section{Introdução}

Neste texto discutimos a educação de crianças indígenas apresentando relatos etnográficos de pesquisas de campo realizadas em três terras indígenas Guarani, no norte do Paraná, habitadas por povos da parcialidade Nhandewa. Buscou-se relatar a participação das crianças nas atividades culturais festivas das comunidades e como são desencadeados processos educativos que contribuem com suas aprendizagens e, consequentemente, com o desenvolvimento identitário e cultural.

Destacamos como a coletividade e espiritualidade dos Guarani permeiam o modo de ser das comunidades e o papel dos mais velhos, dos professores, dos sábios e dos rezadores na educação e formação das crianças e jovens. As reflexões expostas partem de uma perspectiva educacional e cultural, considerando questões sociais e linguísticas das comunidades e como são apropriadas pelas crianças Guarani. A metodologia do trabalho que deu origem ao texto empregou estudos teóricos, observação e registros de campo onde se descreveu a participação das crianças, com seus grupos familiares, nas vivências festivas.

Apresentamos aspectos das organizações socioculturais das Terras Indígenas (TI) Guarani Nhandewa no norte do Paraná, contextualizando-os para caracterizar a realidade em que vivem as crianças Guarani, como interagem e aprendem em suas vivências.

Registramos e descrevemos, especialmente, três eventos comemorativos, no ano de 2015, e que são recorrentes nestas Terras Indígenas: a Festa do Dia do Índio, na TI Laranjinha, município de Santa Amélia; a III Feira de Sementes 
Crioulas Indígenas Ymãu e Mudas Nativas, na TI Pinhalzinho, município de Tomazina, e a II Mostra Cultural Guarani Nhandewa, na TI Ywy Porã, município de Abatiá.

Procuramos destacar aspectos culturais religiosos dos povos Guarani, que são presentes em todos os momentos festivos e que, segundo Schaden (1974), Nimuendajú (1987), Bartolomé (1991), etnólogos clássicos, estudiosos dos Guarani, são elementos que fundamentam o modo de ser destes povos. A Oy Guatsu (casa de reza) é espaço fundamental da produção e reprodução dos conhecimentos ancestrais e propicia relevantes aprendizagens para as crianças.

No texto se evidencia como as lideranças nativas, as comunidades, os rezadores e as rezadoras, as professoras e os professores se organizam para preservar e revitalizar conhecimentos ancestrais e linguísticos visando ao fortalecimento da identidade Nhandewa; e como as crianças, nestes contextos, participam e se inserem nas atividades de forma ativa e se apropriam, assim, de saberes que circulam em suas comunidades.

\section{As terras indígenas Guarani Nhandewa no norte do Paraná}

\section{na atualidade}

No estado do Paraná, estão territorializados povos Kaingang, Guarani e Xetá que vivem na região há aproximadamente dois mil e quinhentos anos. Há ainda a presença de famílias Xokleng. Atualmente existem cerca de 30 Terras Indígenas (TI), das quais 17 são habitadas pelos povos Guarani (PARANÁ, 2012). As TI Guarani são: Araça'í; Kakane Porã; Kuaraí Oguatá; Laranjinha; Koe ju Porã, em Marrecas; Ocoy; Aty Miri; Pindoty; Pinhalzinho; Rio D’Areia; Comunidades em Rio das Cobras; Sambaqui do Guaraguaçú; comunidade em São Jerônimo; Tekoha Anhetete; Tekoha Itamarã; Verá Tupã'i; Ywy Porã e mais cerca de 20 Tekohas situadas em territórios Guarani em Guaira, Terra Roxa e região.
Há vários outros espaços tradicionais que, ocupados por frentes de colonização, estão sendo retomados e reorganizados pelos Guarani no Paraná. Há terras, conforme as citadas, em que os Guarani habitam conjuntamente com os Kaingang e Xetá, em razão da forma como o poder público fez as demarcações no estado.

0 povo indígena Guarani apresenta, no Paraná, pelo menos quatro parcialidades que se autodenominam Ava, Nhandewa, Mbya e Kaiowa. A língua falada por estes povos pertence à família linguística tupi-guarani e há algumas diferenças que demarcam identidades e identificam a ancestralidade, parcialidades de pertencimento. Na região norte do Paraná, especificamente nas Terras Indígenas Laranjinha, Pinhalzinho e Ywy Porã, predomina o subgrupo Nhandewa.

Considerando o objetivo deste trabalho de apresentar reflexões sobre os processos educativos da criança Guarani, fazemos uma breve descrição das três TIs em que a pesquisa de campo se desenvolveu, a fim de contextualizar a temática em questão. Em relação às realidades territoriais, culturais e linguísticas, é preciso levar em conta que: "Além das parcialidades há diferenças que dependem do histórico de demarcação das terras, das lutas e das políticas locais" (FAUSTINO, 2012, p. 241).

Conforme dados do Censo Demográfico de 2010 (INSTITUTO BRASILEIRO DE GEOGRAFIA E ESTATÍSTICA, 2012), existem 25.915 indígenas no Paraná. Em razão da expropriação dos territórios tradicionais, tanto por empresas privadas que tomaram posse de terras indígenas para comercializá-las, com a anuência dos governos estaduais, como por fazendeiros da região, metade desta população foi expulsa das terras e vive como sem-terra ou nas periferias das cidades.

O povo Guarani no Paraná é composto por mais de quatro mil pessoas. As terras onde estão inseridos situam-se em municípios cujo Índice de Desenvolvimento Humano (IDH) é muito baixo. As pequenas parcelas de terras indígenas demarcadas foram sendo cercadas pela 
agricultura mecanizada, o que causa impacto devastador à vida indígena nos Tekohas (terra/ território Guarani) em razão do desmatamento, poluição dos rios e solo, perda acelerada de espécies animais e vegetais e, principalmente, pelo uso de agrotóxicos e monocultura de exportação.

Os conhecimentos ancestrais Guarani dependem da terra e da natureza para se reproduzirem, e há pouquíssimas reservas de mata no estado (FUNDAÇÃo SOS MATA ATLÂNTICA; INSTITUTO NACIONAL DE PESQUISAS ESPACIAIS, 2011). Poucas plantas sagradas têm conseguido sobreviver, o que dificulta e até impossibilita práticas culturais como, por exemplo, o Nimongaraí, ${ }^{1}$ ritual sagrado que, para se realizar, necessita da madeira de Cedro, mel de abelha jataí, milho tradicional, e demais alimentos produzidos por eles próprios (FAUSTINO, 2012).

A luta dos povos indígenas por seus territórios e por continuar vivenciando suas tradições e ensinando-as às crianças e jovens tem se tornado cada vez mais difícil. Segundo dados dos organismos internacionais, os povos indígenas vivem abaixo da linha de pobreza.

A pobreza afeta $43 \%$ da população indígena na região (mais do dobro da proporção de não indígenas), enquanto $24 \%$ de todos os povos indígenas vivem em extrema pobreza $(2,7$ vezes mais que a proporção de não indígenas). Além disso, ter pais indígenas aumenta substancialmente a probabilidade de a pessoa ser criada em uma família pobre, contribuindo para uma armadilha de pobreza que impede o desenvolvimento total das crianças indígenas. (BANCO MUNDIAL, 2015, p. 9).

Diante da situação precária em que os povos indígenas foram colocados nos processos de colonização, ficam sem condições de garantir a sustentabilidade de todos nos Tekohas, demarcados em pequenas aldeias, e muitos membros das famílias necessitam buscar trabalho e renda nas cidades do entorno. Como

1 O Nimongarai é um ritual realizado pelos povos Guarani para consagração do milho e das sementes, e para o batismo, onde são dados os nomes indígenas às crianças e aos adultos. consequência dessa situação e do histórico da invasão dos territórios tradicionais, os Guarani Nhandewa no norte do Paraná, em sua maioria, foram forçados a falar majoritariamente em língua portuguesa. Lutando contra esta situação, as comunidades desenvolvem diversas estratégias de preservação e reprodução da língua Guarani, de forma que as crianças compreendem palavras, expressões, cantos e rezas. As famílias que frequentam a $O y$ Guatsu têm maior contato com a língua e as tradições.

Há ainda a presença de igrejas nas terras indígenas, com situações de batismos cristãos em que quase a totalidade da comunidade deixou de frequentar a Oy Guatsu e seguir as tradições, práticas e ensinamentos ancestrais (BARROS, 2003).

Nesse contexto, a escola é tida por estes povos como um meio para revitalização cultural (FAUSTINO, 2006), na medida em que esta instituição propicia conhecimentos escolares e que, a partir da Constituição Federal de 1988 e legislações complementares permite, também, que as comunidades introduzam, nesse ambiente, conteúdos e procedimentos próprios dos conhecimentos advindos de suas tradições e seus processos próprios de transmissão.

Dentre algumas das ações de revitalização sociocultural, o trabalho coletivo entre as comunidades, instituições parceiras - como universidades, institutos e organizações não governamentais - e as escolas tem possibilitado a realização de projetos e eventos culturais nas terras indígenas, nos quais as crianças participam efetivamente e se apropriam de importantes elementos da cultura Nhandewa.

A TI Laranjinha, localizada no município de Santa Amélia (PR), possui uma área de 284 hectares, na qual habitam aproximadamente 300 pessoas. Algumas famílias possuem renda, mas que depende das condições climáticas, pois a maioria dos trabalhos envolve plantar alimentos, produzir e comercializar artesanato. Algumas famílias têm acesso a programas governamentais como o Bolsa Família. Há empregos públicos temporários, como de professores, 
de agente de saúde e demais funções existentes nas terras indígenas.

Há nessa TI duas igrejas em que o Cristianismo é propagado, uma Católica e outra da Congregação Cristã no Brasil (CCB). Em seus estudos, Barros (2003) constatou que praticamente toda a comunidade havia se convertido e se tornado membro da igreja CCB. Contudo, constatamos em nossas pesquisas de campo que, mesmo aceitando a doutrina da CCB, elementos da espiritualidade Guarani estão bastante presentes, como pode ser verificado, por exemplo, no movimento da comunidade para a reconstrução da casa de reza que se iniciou e foi concluída no ano de 2015.

Na comunidade há a Escola Estadual Indígena Cacique Tudjá Nhanderú, que oferta Educação Infantil e anos iniciais do Ensino Fundamental. A equipe pedagógica da instituição é composta por indígenas e não indígenas, sendo a maioria dos professores Guarani e a diretora uma não indígena. No ano de 2015 havia cerca de 30 crianças matriculadas, moradoras da TI Laranjinha e outras de terras Guarani que, em visita a parentes, acabam residindo ali por período indeterminado.

A TI Pinhalzinho, localizada no município de Tomazina, possui uma área de 593 hectares habitados por aproximadamente 180 pessoas. Sobre a situação socioeconômica desta TI, verificou-se que não há espaço suficiente para que todos tenham roças familiares, havendo severas privações materiais. Para se manterem, contam com o Programa Bolsa Família, aposentadorias dos mais velhos, alguns empregos públicos, como o de professor, de agente de saúde e de pessoal de apoio. Várias pessoas saem todos os dias da aldeia para trabalhar nas cidades mais próximas.

Nessa terra há um grupo familiar extenso que frequenta e mantém ativa a Oy Guatsu, conduzida por Txamõi Guarani. Há espaços de matas, rios e diversos lugares sagrados onde a comunidade realiza atividades tradicionais como caça, pesca e coleta. Há também nesta TI duas igrejas que professam o Cristianismo.
Nessa comunidade existe a Escola Estadual Indígena Yvy Porã, que oferta Educação Infantil e anos iniciais e finais do Ensino Fundamental. A equipe pedagógica da instituição é composta por indígenas e não indígenas, sendo a direção da escola - diretor e pedagoga - formada por indígenas. Observamos que a gestão escolar indígena e o trabalho que está sendo desenvolvido, coordenado pelo diretor, com apoio da pedagoga e professores índios e não índios, têm conferido grande prestígio à comunidade e a tem colocado em posição de destaque na região em razão das mudanças curriculares que vem implementando e a um importante projeto de sustentabilidade, no modelo da agrofloresta, que estão desenvolvendo. No ano de 2015 havia cerca de 40 crianças matriculadas e a escola caminhando para a efetivação de um projeto educativo intercultural onde são aliados conhecimentos étnicos e outros conhecimentos científicos provenientes das matérias escolares.

A TI Ywy Porã (Posto Velho), localizada no município de Abatiá, possui uma área de 1.238 hectares, contudo a terra não está demarcada, fazendo com que cerca de 140 pessoas que ali vivem, em processo de retomada, sobrevivam em condições precárias e sem acesso pleno aos recursos institucionais. Há falta de água tratada, o que os leva a consumirem água de um riacho sujo e poluído. Nos estudos realizados, nos relatos dos mais velhos, constatamos que, desde o início do século XX, há registros de que a terra pertencia aos Guarani, porém foi sendo invadida por fazendeiros que, com diferentes meios, os foram amedrontando até os expulsarem completamente do território tradicional. Ao serem forçados a se retirarem, por doenças que contraíram, perseguições e ameaças, as famílias se abrigaram na TI Laranjinha (PR) e na TI Araribá (SP), onde tinham famílias extensas aparentadas.

No ano de 2005, grupos familiares Guarani se organizaram para iniciar a retomada da antiga terra (FAUSTINO, 2006). Reocuparam seu Tekoha, onde havia sido instalada uma 
fazenda. Os fazendeiros da região reagiram negativamente, de forma violenta. A partir do embate criado, com as intervenções judiciais, os indígenas puderam permanecer na terra, mas sem as mínimas condições necessárias para a sustentabilidade. A comunidade tem contado com alguns recursos advindos das políticas públicas que conseguem acessar.

Nessa comunidade não há igrejas cristãs. A língua e a religião ancestral Guarani se revitalizam nas práticas diárias e na Oy Guatsu. Diante do histórico de retomada, conflitos com a sociedade do entorno e privações da comunidade, compreende-se que a casa de reza tem representado também um espaço de reorganização cultural, bem como mecanismo de equilíbrio e alívio das tensões e ameaças.

No Tekoha há uma escola, denominada Escola Estadual Indígena Nimboeaty Mborowitxa Awa Tirope, que atende as crianças da comunidade ofertando Educação Infantil e os anos iniciais do Ensino Fundamental. Atuam na instituição professores e funcionários indígenas e não indígenas. As condições materiais da escola, desde a retomada, foram mínimas; o prédio era uma casinha antiga, de madeira. Está em construção, no Tekoha, uma pequena escola em alvenaria que oferecerá condições mais adequadas de ensino e aprendizagem.

Nos três Tekohas Guarani Nhandewa, brevemente apresentadas, verificamos que a escola tem sido apropriada por esses povos como um instrumento de luta e um caminho para que as crianças adquiram os conhecimentos escolares e os conhecimentos culturais da ancestralidade Guarani. Considerando que as condições atuais nas quais as comunidades indígenas estão inseridas, conforme algumas que relatamos, impossibilitam o nhade reko (modo de ser pleno dos Guarani), os processos de aprendizagem da criança têm se desenvolvido de forma intercultural e podem ser observados a partir das vivências cotidianas, como, por exemplo, as festividades e atividades coletivas realizadas pela comunidade com o apoio da escola.

\section{A participação das crianças nas festas das comunidades e seus processos educacionais}

Para os povos Guarani, a criança pequena representa um espírito que foi enviado à terra e precisa ser cativado por seus familiares para que se estabeleça aqui neste mundo, com saúde, para que possa crescer e se desenvolver (BARTOLOMÉ, 1991; NIMUENDAJU, 2010). Nesse sentido, as famílias destinam cuidados especiais à criança, a fim de evitar que ela se sinta aborrecida, triste ou fique chorando, pois estas situações são sinais de que não está se acostumando com a vida entre seus parentes, podendo seu espírito deixar o corpo e retornar aos deuses.

Desse modo, os elementos que caracterizam o processo educativo na infância Guarani Nhadewa são os cuidados permanentes, a atenção que recebem dos pais e parentes próximos, as orientações e a autonomia que se lhes atribui. A partir dessa concepção de educação, apresentaremos e analisaremos a participação das crianças em eventos festivos, buscando destacar suas diferentes situações de aprendizagem nos Tekohas, principalmente em eventos festivos nos quais suas ações ganham maior visibilidade.

O Dia do Índio foi instituído pela política indigenista, mas se tornou uma data histórica apropriada pelos povos indígenas e celebrada em todas as terras indígenas no Paraná, sendo preparada pelas próprias lideranças juntamente com suas comunidades e recebendo um forte apoio das escolas. Representa um período em que as alianças da comunidade com o poder público local, parceiros e colaboradores se intensificam, para se conseguir apoio e para a sociabilidade que ocorre com refeições coletivas, apresentações culturais, bailes e, em muitos casos, grandes mostras culturais preparadas pelas equipes pedagógicas das escolas e seus professores.

As Universidades, grupos de pesquisa, pesquisadores e demais parceiros que de- 
senvolvem projetos ou ações sociais junto às comunidades são convidados a contribuir e participar das festas. Fomos convidadas pelas lideranças da TI Laranjinha para a festa em comemoração ao Dia do Índio, envolvendo as comunidades do norte. 0 evento realizou-se no período de 16 a 18 de abril de 2015 . Na descrição do evento, considerando os estudos que temos desenvolvido sobre os sistemas tradicionais indígenas de produção e transmissão de conhecimentos, buscamos destacar a participação das crianças e suas aprendizagens.

Ao chegarmos à TI nos dirigimos à residência do cacique, pois, conforme Fernandes (2003) e Novak (2014), a organização das TI no Paraná, no tocante à estrutura de poder, é baseada no cacique, vice-cacique e suas lideranças. Como o cacique não se encontrava, porque estava buscando apoio e divulgando a festa nos municípios do entorno, nos dirigimos, então, à casa do vice-cacique, onde fomos recebidos por sua esposa, que nos informou estar ele ajudando nos preparativos da festa e que poderíamos ir até o local, o campo de futebol.

No quintal da casa havia crianças se preparando para a festa: dois meninos que estavam colocando seus cocares. Como não sabíamos exatamente como chegar ao local da festa, a mãe pediu a um deles que nos acompanhasse. A criança prontamente se dirigiu a nós, disposta a auxiliar. Esta situação nos permite refletir sobre o papel de mediação que em inúmeras situações é desempenhado pelas crianças indígenas, e como elas aprendem com os mais velhos a recepcionar os convidados ou visitantes e acompanhá-los pela aldeia.

Entendemos que isso ocorre como resultante da forma com que este povo compreende a infância. Para os Guarani Nhandewa, a criança é uma pessoa com autonomia, capaz de tomar decisões e fazer muitas coisas, tendo papel relevante na comunidade. Possui liberdade e está em constante processo de aprendizagem e de ensino daquilo que já sabe fazer. As tarefas que realizam contribuem com sua aprendizagem e desenvolvimento, inserindo-a ativamente nos acontecimentos da terra indígena. Com os cuidados, responsabilidades e orientações que recebe contra os perigos existentes, seu espírito vai se fixando no Tekoha, terra em que habita, e na comunidade à qual foi enviada.

Em seus estudos, Tassinari (2007, p. 22) sinaliza algumas características comuns entre os povos indígenas no que se refere à concepção de infância:

[...] 1) o reconhecimento da autonomia da criança e de sua capacidade de decisão; 2) o reconhecimento de suas diferentes habilidades frente aos adultos; 3) a educação como produção de corpos saudáveis, 4) o papel da criança como mediadora de diversas entidades cósmicas; 5) o papel da criança como mediadora dos diversos grupos sociais.

No decorrer da festa identificamos diversos momentos em que as crianças atuavam como mediadoras, produzindo sociabilidade entre a comunidade e os seus visitantes, característica que corresponde ao quinto aspecto destacado por Tassinari (2007).

Em uma perspectiva pedagógica, destacamos o conceito de mediação a partir da Teoria Histórico Cultural (THC), para a qual a mediação pode ocorrer de duas formas distintas. Primeiro, se refere ao conhecimento como mediador e, segundo, quando uma pessoa que possui maior experiência atua como mediadora (SFORNI, 2008). Nesse sentido, compreendemos que a criança Guarani atua conforme a segunda forma de mediação, pois possui o conhecimento espacial da Tekoha, experiência em transitar nos diferentes lugares e as regras de convivência do grupo, o que possibilita a ela fazer a mediação entre os visitantes e o conhecimento cultural que possui, mesmo sendo pequena, em razão das vivências, da participação, da autonomia e do modo como é educada.

Conforme íamos caminhando pela comunidade, tornou-se possível contemplar a organização e a beleza dos preparativos da festa. Os troncos das árvores estavam pintados com grafismos Guarani, caracterizando o espaço com elementos da cultura. Enquanto todos 
aguardavam o início da festa, um professor Guarani, com um canetão vermelho e outro preto, adornava as crianças com grafismos, pinturas corporais, no rosto. As crianças menores, que tinham entre dois e três anos, ao ver o grafismo das crianças maiores corriam até a fila para serem pintadas também.

0 professor explicou-nos o significado das pinturas corporais, informando que o formato de círculo preenchido em cor vermelha é aplicado no rosto das meninas e que a flecha indicativa, em vermelho e preto, é aplicada no rosto dos meninos. Essa pintura é para ocasiões comemorativas, e há muitas outras, específicas para cada situação. No caso de reivindicações e conflitos, a pintura para meninas não seria mais o círculo vermelho, mas apenas traços pretos; para os meninos seria um traço, como uma tarja na horizontal, localizada nos olhos, perpassando o nariz, podendo ser na cor vermelha ou preta.

Após receberem a pintura corporal, os meninos entraram na área reservada para as modalidades de luta, demarcada com pó de serragem colocado no chão, formando um grande círculo. Ali brincavam de lutar. Várias duplas ao mesmo tempo. Embora o espaço estivesse sendo preparado para a festa, os organizadores não se mostraram incomodados com a presença e brincadeiras das crianças, apenas advertiam para que não jogassem o pó de serragem fora do espaço demarcado.

Mesmo muito ocupados com os preparativos, os adultos que estavam mais próximos observavam os meninos, se comunicavam verbalmente com eles e ensinavam: "Não podem usar as pernas para derrubar o oponente", “Não podem sair do círculo". E assim, de forma oral e na prática, os homens transmitiam as regras das lutas aos meninos, que brincando descontraídos, mas sob orientação e acompanhamento dos adultos, iam se apropriando deste conhecimento ao corrigirem suas posturas, passos e ações durante a luta.

Enquanto os meninos lutavam e brincavam, as meninas estavam próximas às mães, tias, avós e demais mulheres que aguardavam o início da festa e estavam sentadas nos bancos dispostos em um grande círculo. Três meninas vieram até nós, a pedido da pedagoga indígena, professora Rosilda, e nos chamaram para acompanhá-las e sentarmos junto às demais mulheres. Nesta situação também identificamos o papel de mediadoras ocupado pelas meninas no grupo das mulheres.

Essas meninas, ao atenderem ao pedido de Rosilda, que é membro da comunidade, professora e delas aparentada, realizaram uma tarefa que nos pareceu ser especialmente destinada às crianças; se ocuparam de nos inserir no grupo das mulheres, evidenciando que, entre os Guarani, as meninas maiores acompanham as mulheres e os meninos maiores, os homens.

Aos poucos as demais famílias chegavam ao campo e se aproximavam, e logo chegou, de ônibus, a comunidade Guarani da aldeia Ywy Porã com as famílias que participariam da festa. As crianças das duas aldeias foram se juntando e se interessando pelas pinturas corporais dos que já estavam pintados. 0 grafismo pintado nas crianças do Ywy Porã se diferenciava das pinturas da comunidade do Laranjinha. Eram traços horizontais, nas cores vermelho e preto, localizados abaixo dos olhos, perpassando o nariz, de uma extremidade a outra da face. Além do rosto, fizeram grafismos nas pernas e braços e, então, algumas das crianças da TI Laranjinha logo estavam com grafismos nas pernas e braços também. Ou seja, além de aprenderem com os adultos, as crianças aprendem umas com as outras também.

Tendo sido finalizados os preparativos, a atividade que deu início à festa foi uma apresentação de dança das crianças da TI Laranjinha. Em pares, aproximadamente 20 crianças se posicionaram ao redor do círculo de serragem no chão. As meninas, lado a lado, em uma reta, e os meninos, de forma oposta às meninas, a uma distância de cerca de dois metros. Algumas crianças estavam adornadas. As meninas utilizavam na cabeça uma tiara feita com sementes, 
um adorno nos tornozelos e roupa confeccionada com sementes e grafismos. Dois meninos estavam com belos cocares. Identificamos que são filhos de lideranças.

A apresentação da dança ocorreu acompanhada de música tocada por um professor indígena e um grupo composto por jovens Nhandewa, que cantavam, tocavam o mbaraká, ${ }^{2}$ violão e tambor. Os sons das vozes eram suaves, sincronizados, agradáveis, e a melodia da música Guarani mobilizou a atenção de todos. Conforme os passos da dança se seguiam, as crianças, que tinham entre seis e onze anos, se comunicavam entre si, ajudando umas às outras, indicando qual seria o próximo passo.

A próxima apresentação foi uma dança realizada pelo grupo da comunidade de Ywy Porã, que se posicionou em um grande círculo, adultos e crianças, homens e mulheres. Todos cantavam e dançavam, com passos sincronizados, de beleza extrema e em admirável concentração.

A terceira atividade apresentada pelos Guarani Nhandewa foi o arco e flecha. Cada indígena que iria participar já estava com seu próprio arco e com a flecha, muito adornados. Algumas crianças também carregavam os seus instrumentos, que eram de tamanho proporcional a sua altura. Os participantes se posicionaram lado a lado em uma reta, ficando bem distantes do alvo, composto por placas de isopor pintadas. Todos - homens, crianças e mulheres - atiraram mantendo a mesma distância do alvo, mesmo as crianças não puderam se aproximar ou ter qualquer tipo de vantagem.

Enquanto a atividade era desenvolvida, os organizadores trouxeram água; nos aproximamos para tomar e permanecemos ao lado do recipiente com água. Logo se aproximou uma menina com copo de vidro e nos entregou, oferecendo água gelada. Como já havíamos tomado, agradecemos. Mais uma vez foi pos-

20 mbaraká é um instrumento considerado sagrado para os Guarani. Ele é semelhante a um chocalho, é feito com cabaça e madeira, sendo decorado com grafismos, penas e sementes. É utilizado para rezas, celebrações na casa de reza e também para as apresentações de danças (NIMUENDAJÚ, 2010). sível verificar um dos papeis das crianças, desempenhado na festa: a atenção e os cuidados com os visitantes e a mediação que realizam em diferentes situações com os visitantes no decorrer da festa.

Entre os participantes dessa atividade destacamos a presença de um importante tudjá, pessoa mais velha, Sr. Dercílio, antigo morador da TI Laranjinha, muito respeitado pelas lideranças, familiares e crianças. Ele estava presente desde o início da festa com sua esposa, D. Maria de Lourdes Lourenço, também uma pessoa de grande prestígio, sempre citada por muitos membros da comunidade ao se referirem aos falantes da língua Guarani e aos sábios da aldeia.

O Sr. Dercílio relatou ter nascido na Aldeia guarani do Araribá, no estado de São Paulo, afirmando que há 69 anos vive na TI Laranjinha. Após sua participação na atividade de arco e flecha, única em que se inseriu, tivemos a oportunidade de conversar. Indagamos a respeito das músicas e dos instrumentos musicais como o mbaraká. Ele nos explicou que é um instrumento sagrado e, por isso, não pode estar em qualquer lugar ou com qualquer pessoa, nem mesmo com crianças indígenas, exceto no caso de um adulto estar lhes ensinando algo relacionado à espiritualidade Guarani. Sobre isso, Nimuendajú (1987) afirmou ser o mbaraká um instrumento sagrado Guarani, relatando que "os índios sempre ficam extremamente constrangidos, quando um estranho indiscreto pega um maracá e começa a brincar despreocupadamente [...]" (NIMUENDAJÚ, 1987, p. 80).

Enquanto conversávamos, uma criança pequena, de aproximadamente quatro anos, se aproximou e pediu emprestado ao Sr. Dercílio seu arco e suas flechas para participar da competição. Era seu bisneto, a quem disse não e explicou que cada um deveria ter o seu próprio instrumento. Em seguida, uma mulher casada com um de seus netos também lhe pediu emprestado, para a mesma finalidade; ele negou novamente, explicando o porquê. A situação nos permitiu duas percepções, embora 
devam existir outras tantas. Primeiro, que as crianças devem aprender a ter suas próprias responsabilidades e providenciar, previamente, seus próprios instrumentos, adequados ao seu tamanho; segundo, que a relação entre o instrumento e seu dono é única, de modo que não o emprestou nem a uma criança, nem a uma mulher adulta de seu grupo familiar.

Retomando as atividades esportivas, o período da tarde se iniciou com a luta $U k a-u k a .^{3}$ As crianças, especialmente os meninos, se mostravam interessadíssimos, e em torno do círculo aguardavam a sua vez de lutar. Após esta atividade ocorreu a corrida de toras, da qual apenas os homens participaram. Não havia toras pequenas e leves; cremos, então, que seja uma atividade apenas de adultos. Em seguida, os adultos fizeram a corrida com lança. Apesar de as crianças não participarem efetivamente nestas modalidades, sempre estavam por perto torcendo, observando e repetindo, verbalmente, as regras do jogo.

Tendo finalizado essas modalidades de corrida, se iniciou a luta Uru Tudjá (galo velho). Com apenas um pé no chão e a mão no peito, o lutador deveria fazer com que seu oponente colocasse os dois pés no chão, por meio de empurrões com o peito, sem utilizar as mãos e sem cotoveladas um contra o outro. Desta atividade participaram apenas os homens, mas nos momentos em que o círculo delimitado ficava desocupado, as crianças corriam para lá e, em duplas, todas ao mesmo tempo, iniciavam suas próprias lutas, a partir do que observaram da realização dos adultos. Ao nosso ver esse é um dos elementos mais relevantes do sistema de educação Guarani, a aprendizagem pela observação e imitação.

Para a Teoria Histórico Cultural, cujos princípios centrais foram criados por Vigotski, a imitação possibilita a aprendizagem e o desenvolvimento da criança. À medida que as crianças lutavam, imitando os mais velhos, estavam

3 A luta Uka-uka é uma das atividades tradicionais realizadas pelos Guarani, constituindo-se uma modalidade de luta corporal. praticando o que vivenciaram, rememorando, experienciando as regras do jogo e educando seu corpo e seu comportamento.

Todos conhecem o enorme papel da imitação nas brincadeiras das crianças. As brincadeiras infantis, frequentemente, são um eco do que a criança viu e ouviu dos adultos. No entanto esses elementos da experiência anterior nunca se reproduzem, na brincadeira, exatamente como ocorreram na realidade. As brincadeiras da criança não são simples recordação do que vivemos, mas uma reelaboração criativa de impressões vivenciadas. É uma combinação dessas impressões e, baseada nelas, a construção de uma realidade nova que responde às aspirações e aos anseios da criança. (VIGOTSKI, 2009, p. 16).

Desse modo, compreende-se que os eventos festivos nas aldeias possuem um papel importante na educação das crianças, tendo em vista que, nesses momentos, elas têm oportunidades de se apropriar de elementos da ancestralidade, como os jogos tradicionais, que não são mais praticados com frequência na comunidade, em razão de fatores já mencionados.

No evento observado foi possível constatar que, em todos os momentos, as crianças estavam presentes; mesmo não participando de alguns dos jogos tradicionais, estavam atentas, interessadas, e aprendendo pela observação das práticas dos adultos.

Pinturas corporais, algumas danças e jogos tradicionais têm ocorrido, especialmente, nestes eventos, pois as difíceis condições em que vivem as comunidades Guarani do norte do Paraná, na atualidade, têm oferecido poucas oportunidades, espaço e tempo para grandes celebrações que, conforme relato de etnólogos, ocorriam frequentemente e reuniam todos os membros das comunidades.

Nosso segundo registro retrata a III Feira de Sementes Crioulas Indígenas Ymãu e Mudas Nativas, realizada na TI Pinhalzinho, município de Tomazina, por meio do trabalho coletivo das lideranças, da Escola Estadual Indígena Yvy Porã e da comunidade. Esta Feira objetivou, além de proporcionar um momento de 
exposição e trocas de sementes entre os participantes, apresentar os trabalhos escolares desenvolvidos pelas crianças com seus professores, considerando conhecimentos da cultura Guarani, como o tempo bom para o plantio, a importância de uma alimentação saudável, formas de preservar as sementes tradicionais e de transmissão destes conhecimentos às gerações.

A participação nessa Feira, que ocorreu nos dias 8 e 9 de outubro de 2015, foi possível por meio do convite feito pelo cacique, Sr. Sebastião Alves, e pelas lideranças da comunidade. Observamos a organização e a participação das crianças, bem como elementos sobre o processo educativo Guarani e como se expressam em momentos festivos.

Ao chegarmos na aldeia, antes de nos dirigirmos ao local da Feira, visitamos, primeiramente, o cacique da TI, que nos recepcionou informando-nos que o evento ocorreria em um barracão existente na comunidade. Fizemos uma caminhada pela aldeia e, ao chegarmos ao local, havia sido organizado um palco, montado com bambus amarrados com cipó e presos com arames às árvores mais próximas. Havia alguns bancos de madeira ao redor do palco formando um semicírculo, para recepcionar os convidados.

No centro desse local havia um galho de árvore com dois balanços, feitos de corda e um pedaço de madeira (tábua), que estavam suspensos, evidenciando ser um local em que as crianças costumam brincar. No chão, bem ao centro do semicírculo formado pelos bancos, havia brinquedos alternativos como um skate feito de madeira com rodas reutilizadas, provavelmente encontrado pelas crianças nos arredores da cidade do entorno, para onde se dirigem com seus familiares ocasionalmente.

Ao redor desse local havia quatro casinhas feitas com bambu e sapé para as crianças brincarem. Havia neste espaço algumas cordas esticadas, feitas de tecido (semelhante à malha) na qual havia algumas tiras de taboa. Soubemos que eram provenientes de uma atividade escolar feita por uma das professoras da escola com o auxílio dos mais velhos Guarani da comunidade, na qual ensinaram às crianças como fazer saias tradicionais usadas nas apresentações. Em uma das árvores, próxima às pequenas casas, havia uma corda com alguns nós, distantes uns dos outros. Era outro tipo de brinquedo, no qual as crianças costumam se pendurar para balançar.

O local nos chamou a atenção pois, para a Teoria Histórico Cultural, a brincadeira não é apenas uma simples atividade para passar o tempo; tem um papel significativo no desenvolvimento da criança. Nessa perspectiva, ao brincar, a criança reelabora vivências que tem em seu cotidiano, imitando, inventando, recriando e desenvolvendo sua imaginação e criatividade. Nesse sentido, verifica-se que o brincar, e também os brinquedos elaborados com e para as crianças, constituem importantes momentos de aprendizagem, de sistematização das experiências vividas pelas crianças Guarani da comunidade.

Observamos que enquanto as crianças transitavam da casa do cacique ao barracão, a chuva que caía no momento não as impedia de se movimentar o tempo todo. Ora corriam, ora caminhavam devagar, com cuidado, esquivando-se de poças e lugares com muito barro, umas com guarda-chuvas, outras sem. Nestas idas e vindas, dois meninos, de aproximadamente 10 anos de idade, estavam com um petynguá (cachimbo), usando-o e manuseando-o de maneira semelhante aos adultos. Durante toda a Feira, apenas alguns homens e estes meninos utilizaram o petynguá. Em nossas observações não vimos crianças pequenas e nem mulheres fumando, situação que nos remete aos escritos de Schaden (1974) ao relatar que as crianças Guarani Mbya não fumavam com medo de se sentirem mal.

No barracão da comunidade, duas famílias montaram uma mesa com artesanatos para comercialização. Uma das famílias, ao chegar ao local da Feira, apresentava, entre seus membros, diversos adornos no corpo e grafismos nos braços. As crianças observaram, se 
interessaram e pediram para serem pintadas também. Os adultos imediatamente atenderam ao pedido e fizeram grafismos nas crianças com canetões nas cores vermelho e preto.

As mesas com as sementes tradicionais a serem expostas foram sendo organizadas por diferentes famílias. Em relação às sementes nelas dispostas, observamos uma variedade de milho, em muito maior quantidade do que as dos demais alimentos como abóbora, feijão e hortaliças. Sobre isso mencionamos o valor desse alimento para esse povo indígena.

Na lavoura Guarani, o cultivo do milho assume importância incomparavelmente superior à de qualquer outra espécie vegetal. 0 milho, além de ser uma das principais fontes de alimento (sobretudo entre os Ñandéva e os Kayová), constitui a principal matéria-prima para a fabricação de chicha (bebida fermentada) e é, além disso, produto que sempre encontra mercado fora da aldeia. (SCHADEN, 1974, p. 40).

Apesar de não termos registrado nenhum relato sobre a fabricação ou uso da chicha entre os Guarani, no norte do Paraná, constatamos que nas comunidades o milho é considerado um alimento sagrado, o que se soma a sua importância para estes povos.

Durante o processo de organização das sementes em embalagens para troca, as crianças participaram. Estavam, antes disso, caminhando, correndo ou brincando de pega-pega, livremente, no barracão. Ao verem os mais velhos ensacando as sementes, começaram a ajudar. Elas não eram repreendidas quando, por algum motivo, deixavam de ensacar as sementes. Observamos que faziam esta atividade livremente, por iniciativa e interesse próprios, sem terem sido chamadas ou dispensadas por seus familiares.

Tendo finalizado a organização das sementes para troca no espaço da Feira, com os materiais escritos (cartazes, banners, faixas) elaborados pelas crianças com a orientação de seus professores, iniciaram-se as apresentações orais anunciadas pelo cacique e algumas lideranças, após agradecerem a presença dos convidados. 0 espaço foi organizado de modo a expor as atividades escolares por temas como: entrevistas com os tudjá, tabelas informativas, conceitos sobre produção de roças e ensinamentos sobre um plantio consciente e livre de venenos. As crianças foram se organizando em duplas ou em grupos e se posicionando, conforme uma ordem previamente definida com os professores.

No decorrer da exposição, apresentaram os estudos e pesquisas que realizaram na escola, sob orientação do diretor e da pedagoga indígenas e a mediação de seus professores, índios e não-índios, contemplando temas sobre a roça tradicional, o manejo da terra e seus benefícios, variadas técnicas envolvidas nestas atividades. $\mathrm{Na}$ apresentação utilizaram um roteiro escrito, disposto em um pequeno cartaz feito à mão sob papelão, em cujo verso havia adornos e grafismos indígenas.

Algumas crianças optaram por falar sem olhar ou ler seus roteiros. Relataram oralmente os estudos realizados, as pesquisas e os registros feitos. Contaram sobre as conversas e vivências que tiveram com os mais velhos, atividade planejada e organizada pela direção, equipe pedagógica da escola e professores, com o apoio da comunidade.

Após as apresentações, conversamos com as crianças. Procuramos não direcionar a conversa, queríamos ouvi-las, saber como se sentiam estando envolvidas em uma atividade como esta, que abrangia conhecimentos étnicos e conhecimentos escolares. $\mathrm{O}$ assunto artesanato se destacou nas falas. Perguntamos se faziam, se vendiam. Uma das crianças relatou que ajuda sua família a coletar sementes, mas que nunca ficou responsável por vender os artesanatos; informou que um dos visitantes da Feira lhe falou que queria comprar o colar que estava usando. Disse-nos que não pode vender porque pertencia a ele e ao irmão mais novo, e este não aceitou vender, mas afirmou-nos que, se fosse só dele, venderia.

Nesse momento outra criança se manifestou expressando o desejo de vender um dos colares 
que estava usando. Lamentou por não a terem procurado, dizendo que, com certeza, venderia. Algumas crianças nos contaram, muito entusiasmadas, que sabem fazer colares com sementes. Segundo elas, aprenderam com os mais velhos, que as ensinaram.

Verificamos nas falas das crianças que elas possuem autonomia para tomar decisões, neste caso em relação ao que têm interesse em aprender e aos objetos que produzem. Reportamo-nos, neste tema, ao que foi registrado por Schaden (1974). A partir de estudos sobre os povos Guarani, o autor afirmou que:

0 pesquisador, procurando adquirir para a coleção etnográfica algum objeto - um cesto, por exemplo - que pertença a uma criança, não o consegue sem a anuência desta, embora talvez ofereça, a título de remuneração, um utensílio muito cobiçado pelos pais. (SCHADEN, 1974, p. 48).

A situação apresentada pelo autor e nossas observações nos eventos culturais permitiunos perceber elementos que permeiam as relações entre as crianças e os adultos, ancoradas no sistema tradicional de conhecimento Guarani Nhandewa, possibilitando que a criança, desde pequena, tenha a oportunidade de tomar suas próprias decisões.

$\mathrm{Na}$ continuidade da feira, as crianças matriculadas na Educação Infantil e também do $1^{\circ}$ ao $5^{\circ}$ ano do ensino fundamental apresentaram dramatizações que contaram a história de como os Guarani Nhandewa conseguiram e de que modo preservam as sementes do awaty, milho tradicional, a partir de relatos que coletaram com D. Nica, uma sábia, rezadora, e registraram com a mediação de seus professores. Apresentaram ainda, um mbojare, dança circular, ao final.

Segundo estudos dos etnólogos clássicos dos Guarani,

[...] tudo que diz respeito ao milho se associa ao mundo sobrenatural. É verdade que se fala em cerimônias correspondentes também para as outras plantas de cultivo - mandioca, batatadoce, feijão, abóbora, morango, fumo, algodão - mas estas parecem limitar-se ao 'batismo' dos primeiros frutos, espécie de exorcismo da 'primeira cestada'. (SCHADEN, 1974, p. 42).

A apresentação das crianças enfatizou exatamente a origem divina do awaty colorido. $\mathrm{Na}$ narrativa por elas registrada, as sementes provêm de Nhanderu (Deus) e foram entregues nas mãos de um Txamõi (rezador) durante a realização de um ritual, e ao serem plantadas produziram o milho colorido.

Além desses momentos terem revelado fortes elementos da espiritualidade Guarani, a Feira encerrou-se com uma celebração especial, na qual o Txamõi da comunidade fez a consagração das sementes.

Nas exposições dos trabalhos escolares pelas crianças, nas falas do diretor indígena, $\mathrm{e}$ das lideranças observamos que a iniciativa da comunidade do Pinhalzinho em organizar esta Feira, inserindo a escola como uma instituição central neste evento, reflete a importância desta na formação das crianças e demonstra a busca de articulação entre o sistema de educação tradicional Nhadewa, os conhecimentos étnicos deste povo e o sistema educacional escolar por meio do qual acessam outros conhecimentos científicos.

Nessa articulação estão revitalizando saberes, dando-lhes maior visibilidade, ampliando a aprendizagem das crianças e a conscientização da comunidade sobre a relevância de revitalizar conhecimentos ancestrais para uma produção sustentável. Evidenciou-se a organização coletiva na produção de alimentos saudáveis, sem agrotóxicos e sem uso de sementes transgênicas (fracas), acentuando-se a importância das roças familiares, que várias famílias não conseguem mais praticar em razão do desgaste e da poluição do solo, falta de espaço na aldeia ou outros problemas. Propiciou-se, entre as comunidades Nhandewa do norte do Paraná, a circulação e revitalização de sementes e técnicas advindas dos conhecimentos ancestrais Guarani.

Por decisão e iniciativa da comunidade do Pinhalzinho, os conhecimentos Nhandewa têm-se articulado mais com os conhecimentos escolares por meio de projetos que estão sendo 
elaborados com conteúdos e práticas pedagógicas desenvolvidas a partir de pesquisas com os mais velhos, os sábios, em diferentes espaços da comunidade e com envolvimento ativo das crianças e dos professores índios e não índios.

A vivência das crianças em atividades da comunidade, como a Feira de Sementes do Tekoha Pinhalzinho, que oportuniza o encontro com parentes de outras aldeias, ao nosso ver, tem lhes proporcionado grande aquisição dos conhecimentos culturais de seu povo, revitalizados e disseminados por meio do trabalho coletivo entre a comunidade e a escola, cuja gestão é indígena.

Segundo Vigotski (2012, p. 116), "A aprendizagem escolar orienta e estimula processos internos de desenvolvimento". Desse modo, consideramos que a Feira movimentou a aprendizagem das crianças, pois teve como tema os conhecimentos étnicos e possibilitou estudos e pesquisas sobre roças familiares e técnicas da agrofloresta.

Outro registro que aqui descrevemos refere-se a uma Mostra Cultural, atividade comunitária e escolar em que as crianças indígenas pesquisam e estudam sobre temas desenvolvidos no ano letivo e apresentam os resultados e descobertas a que chegaram. A então intitulada II Mostra Cultural Guarani Nhandewa ocorreu nos dias 11, 12 e 13 de novembro de 2015, na TI Ywy Porã, município de Abatiá.

Ao chegamos à TI nos apresentamos ao cacique. Neste momento, uma das lideranças nos recepcionou e nos conduziu ao local do evento. As crianças que ali estavam se aproximaram e também nos recepcionaram, se prontificando a ajudar a carregar nossas bolsas.

Esse Tekoha é uma terra que está em processo de reocupação, que ainda não foi demarcada. No espaço "barracão" da escola, onde estavam em exposição as atividades realizadas pelas crianças, havia várias mesas com artesanatos, e nas paredes, cartazes com trechos e imagens extraídos de clássicos que estudaram a cultura Guarani.

Havia um mural com nomes de plantas medicinais que existem na aldeia, um ramo ou semente de cada uma e a indicação de como eram e para que eram usadas. Havia, também, vários desenhos ilustrando os espaços da terra indígena. Em outra mesa estavam alguns dos alimentos tradicionais dos povos Guarani, como o bolo de milho, espigas de milho amarelo, branco e colorido; coró (vivos) e formiga saúva (assadas); cada um dos alimentos estava disposto em uma porunga e identificado com os nomes em língua Guarani.

À noite participamos de uma reza em preparação para dois casamentos que ocorreriam no encerramento da Mostra, reforçando a espiritualidade dos Guarani, pois ambos os casais já são casados há algum tempo, mas aproveitaram a oportunidade para receber a benção do Txamói. Na Oy Guatsu, descalços, fizeram o mbodjeré, conduzido pelos rezadores, na frente das cruzes que estavam do lado de fora e também do lado de dentro, em volta da madeira que sustenta a casa de reza. 0 Txamói, proveniente da TI Pinhalzinho, já estava lá, juntamente com a sua família. Enquanto colocava seus adornos, dois homens acenderam uma fogueira dentro da Oy Guatsu.

Em toda a celebração o Txamói utilizou a língua Guarani; apenas no final falou algumas palavras em português, pedindo aos indígenas para lutarem, ficarem firmes e resistirem no território onde muito de seus ancestrais viveram, lutaram e morreram.

A cerimônia teve a participação de homens e mulheres, foi longa e com algumas pausas. Foi possível observar que, conforme relatos de Schaden (1974) e Nimuendajú (1987), este é um ritual extenso, no qual todos permanecem em pé o tempo todo e movimentam seus instrumentos. Segundo Nimuendaju (1987), no passado esse ritual também era um meio para que os homens Guarani mantivessem um bom preparo físico, de modo que alguns chegavam a cair em razão da fadiga e da exaustão da cerimônia.

No dia seguinte, a Mostra iniciou-se com a apresentação de um grupo de dança da TI Barão de Antonina, situada na região. Os integrantes do grupo de dança estavam descalços 
e com vestimenta adornada de grafismos, feita de estopa e pintada com tinta vermelha, azul, verde e preta. Houve, também, apresentações de dança das comunidades da TI Ywy Porã e da TI Laranjinha.

Após as apresentações fizemos uma trilha pela mata, na qual as crianças nos mostraram armadilhas de caça. Encontrávamos as armadilhas pelo caminho e as crianças iam à frente ensinando seus modos de funcionamento e quais animais se pode capturar em cada uma delas. As armadilhas apresentadas foram: Arapuka (arapuca) grande e pequena, para capturar animais como pomba do ar, saracura e nhambu; o mondepi (quebra pescoço), para capturar tatu, quati e paca; o mundéu, também para tatu, quati e paca; a armadilha jukwia (juquiá), para diversos pássaros; o nihoã (laço), para capivara e porco do mato; o pari, para peixes, armadilha que, segundo nos explicaram, deve ser colocada onde o rio desce com mais força.

Na manhã do último dia da Mostra Cultural, as crianças da comunidade Ywy Porã apresentaram duas danças. Elas estavam com roupas brancas de algodão, com grafismo preto e vermelho, confeccionadas no Tekoha pela própria comunidade. 0 grafismo na roupa dos meninos era circular e na das meninas, um trançado. Estavam descalços e com pinturas corporais. Alguns dos meninos usavam colares e kangwá (cocar). Havia no grupo de crianças algumas bem pequenas, de aproximadamente três anos. Os maiores as ajudavam a acompanhar os paços da dança com paciência, quando se equivocavam. A dança realizou-se ao som de violino, violão, mbaraká e batuque.

Com a finalização das danças, iniciaram-se as apresentações das crianças da TI Pinhalzinho. Elas fizeram uma exposição sobre as constelações da Ema (Guyra Nhandu), Anta (Tapi'i) e Veado (Guaxu), baseados nos estudos sobre etnoastronomia do pesquisador Germano Bruno Afonso, cujos textos foram selecionados e estudados pelos professores.

Em seguida, crianças menores, da educação infantil, apresentaram, com fundo musical, as fases da lua utilizando telas a óleo com ilustrações. Apresentaram também um relógio solar elaborado a partir de entrevistas realizadas com tudjas (mais velhos) da comunidade e um Calendário Ilustrado, também realizado a partir do conhecimento dos mais velhos. Nestes trabalhos apresentaram o tempo velho (outono e inverno) e o tempo novo (primavera e verão), que é considerado pelos Guarani como sendo propício para o plantio.

No período da tarde as atividades prosseguiram no campo de futebol da comunidade, onde se realizaram alguns jogos tradicionais indígenas. 0 primeiro foi o arco e flecha, seguido pela corrida de toras e o arremesso de lanças. Para as crianças, exclusivamente os meninos, a diversão estava em atirar ao alvo com suas pequenas flechas. As meninas brincavam de futebol com os meninos maiores do lado esquerdo do campo. A última atividade foi a luta corporal, e, nos intervalos, as crianças corriam para dentro do círculo delimitado para lutarem, cada um com seu par, com o objetivo de ganhar a luta.

Sobre esses momentos, observamos que enquanto as crianças brincavam de luta, mesmo não sendo uma competição, elas estavam exercitando e se apropriando das regras do jogo. Enquanto elas brincavam, os adultos riam e se divertiam dando-lhes sugestões: "Segura na perna dele!”, “Vai com força!”, “Cuidado! Estão saindo da marcação do círculo!”, e outras orientações. No final da modalidade masculina e feminina deixaram que uma dupla de meninos de aproximadamente três anos de idade "lutassem". Eles haviam permanecido ali assistindo por muito tempo, e, ao "lutarem", ficaram atentos e tentando ouvir as orientações que os pais e parentes lhes davam.

Compreende-se que eventos festivos ou escolares, como se caracterizou a Mostra Cultural, se constituem em importantes vivências e aprendizagem para as crianças. As ações livres, a convivência com os mais velhos, a observação e participação nas atividades lhes possibilitam colocar em prática histórias e narrativas que 
ouviram, ampliando sua apropriação de conhecimentos da cultura e do modo de ser Guarani Nhandewa.

\section{A expressão da espiritualidade entre os povos Guarani}

A espiritualidade é um dos elementos centrais que caracterizam os povos Guarani. Em seus escritos, Schaden (1974) afirma que o modo de ser Guarani se fundamenta exclusivamente na religião, fazendo com que esta predomine em todos os aspectos da cultura. Constatamos, durante a participação na Feira de Sementes e na Mostra Cultural, que a oy Guatsu, casa de reza, possui um grande significado, de modo que nos eventos houve celebrações e rituais, o que evidencia a não separação do aspecto religioso dos demais que constituem a cultura e a sustentabilidade Guarani.

Sobre as igrejas que professam o cristianismo nas TI, compreendemos, conforme Schaden (1974), como resultado de alianças políticas, porém se evidencia que, mesmo convertidos ou em contato com outras religiões, muitos dos Guarani não abandonam totalmente as crenças tradicionais. Este talvez seja um dos motivos atribuídos à reconstrução da casa de reza, no Laranjinha, onde, segundo Barros (2003), a população aderiu, quase que na sua totalidade, à CCB.

A esse respeito, Barros (2004, p. 144) afirma que "[...] a adesão ao cristianismo não deve ser considerada unicamente como a aceitação de algo imposto e diante do qual não há escolha, mas sim uma tomada de posição diante da situação de contato imposta ao grupo". Faustino (2006) pontua que a mobilidade oferecida pela CCB, mesmo que totalmente distinta da mobilidade tradicional Guarani, possibilita o contato e a visita a familiares e amigos de outras comunidades, além das doações, celebrações, acesso a instrumentos musicais e cantos, em que, por muitas vezes, inclusive, utilizam a língua Guarani nos hinos religiosos.
Observamos que é forte a presença das crianças das comunidades do norte do Paraná nas celebrações das igrejas evangélicas com suas famílias. Este é um tema a ser estudado, pois Schaden (1974) registrou que, entre os Guarani Nhandewa, desde bem pequenas as crianças participavam das cerimônias realizadas na comunidade, o que lhes permite rápida aprendizagem sobre o patrimônio espiritual do grupo, aguardando apenas que sua reza lhe seja manifesta por sonho. De acordo com a comunidade estudada pelo autor, as rezas não podem ser ensinadas à criança porque é própria de cada pessoa, que deve aguardar a chegada da sua por meio de sonho.

Nas pesquisas de campo realizadas, verificamos que, atualmente, mesmo havendo a casa de reza nas terras indígenas, não há encontros e celebrações muito frequentes que envolvem todos de uma comunidade, conforme narrou Nimuendaju (1987) no começo do século XX.

Diante desse contexto verificamos que os momentos festivos da aldeia, nos quais sempre há celebrações e rituais, configuram-se como importantes meios pelos quais as crianças têm-se apropriado de conhecimentos sobre a espiritualidade Guarani.

Na Feira de Sementes, por exemplo, houve a realização de uma reza para abençoar as sementes. As crianças estavam presentes e, mesmo não participando efetivamente da reza, observaram atentas e participaram dos cantos. Durante os três dias de Mostra Cultural houve rezas à noite e, espontaneamente, por decisão própria, as crianças participaram, sem que os pais lhes chamassem. Estes momentos se constituem como vivências socioculturais em que as crianças se apropriam do modo de ser de seu grupo familiar, o que vai ao encontro dos escritos de Leontiev (1978, p. 284), ao afirmar que cada geração “[...] apropria-se das riquezas deste mundo participando do trabalho, na produção e nas diversas formas de atividade social [...]".

A respeito das rezas cantadas, Schaden (1974) relata que as crianças logo aprendem, 
pois estas são utilizadas como canção para que as crianças menores durmam, o que foi constatado por ele entre os Nhandewa do Itariri. Em seus estudos, esse autor destacou como um dos aspectos principais da infância Guarani a autonomia, que, consequentemente, permeia o processo educativo. "A criança Guaraní se caracteriza por notável espírito de independência. Na medida em que lho permitem o desenvolvimento físico e a experiência mental, participa da vida, das atividades e dos problemas dos adultos" (SCHADEN, 1974, p. 59).

Entendemos que a autonomia da criança indígena advém da organização sociocultural dos grupos étnicos e, no caso dos Guarani, tem profunda relação com o modo espiritual como a infância é concebida. Em seus relatos, Nimuendajú (1987) afirma que para alguns Guarani, a criança pode ser o espírito de algum antepassado que já faleceu, e, neste caso, ela possui muito conhecimento, crença que justifica o respeito, a liberdade e a autonomia que permeia o processo educativo da criança.

\section{Conclusão}

Compreende-se que a sociabilidade atual em que vivem as comunidades Guarani do norte do Paraná e as diferentes maneiras que encontraram para expressar a ancestralidade é decorrente do histórico de ocupação de seus territórios tradicionais e da forma de demarcação das terras, estabelecida pela legislação brasileira.

A drástica diminuição dos territórios associada ao desmatamento do entorno e uso de agricultura mecanizada com sementes transgênicas, poluição dos rios e perda da floresta nativa acarreta a diminuição dos recursos naturais e da sustentabilidade indígena nos Tekohas Guarani Nhandewa.

Essa situação influencia profundamente o modo de ser Guarani, que tem se reconfigurado diante da realidade em que vivem, interferindo no processo educativo da criança. Restam poucos momentos de vivência das crianças com os mais velhos em comunidade, no cotidiano nas aldeias, pois grande parte dos adultos e jovens precisa arrumar emprego, ir trabalhar fora da aldeia, e as crianças passam parte do dia na escola. Em alguns Tekohas, como o Pinhalzinho, observa-se uma forte mobilização da comunidade, da direção e da pedagoga - que são indígenas -, junto com os professores, a fim de construir uma educação intercultural associando os conhecimentos étnicos com outros conhecimentos científicos que circulam no currículo escolar.

Desse modo, compreendemos que estes movimentos, festas e os eventos coletivos, como a comemoração do Dia do Índio, a Feira de Sementes e a Mostra Cultural, têm possibilitado importantes vivências em que as crianças Guarani têm tido contado com conhecimentos e práticas culturais de seus antepassados. Entendemos que, conforme as crianças observavam, participavam e circulavam pelos espaços onde ocorreram os eventos, elas estavam se apropriando do modo de ser Guarani na atualidade.

Quando as crianças eram pintadas com os grafismos Guarani, mesmo não sendo da forma tradicional, elas ouviam e compreendiam o significado de cada traço. Enquanto presenciavam a venda de artesanatos, elas observavam como era feita a negociação. Observando os adultos, estavam sempre presentes e dispostas a recepcionar os visitantes. Ao brincarem, elas atribuíam sentido aos jogos tradicionais, a partir de sua própria visão. Entendemos que estas situações, como as demais descritas no texto, se configuram como momentos educativos, que articulam o sistema tradicional de educação Guarani com os conhecimentos escolares que possibilitam a ampliação das aprendizagens das crianças.

Constatamos, ainda, que a autonomia atribuída à criança permeia todo o processo educativo, como um reflexo da espiritualidade Guarani, da forma como concebem a criança, do respeito e do valor que elas possuem para as comunidades. 
Entendemos que, por meio dessa autonomia a criança, desde bem pequena, tem oportunidade de tomar algumas decisões próprias, com liberdade de acompanhar os adultos em suas atividades, assim como participar das pesquisas, planejamentos e ações escolares.

\section{REFERÊNCIAS}

BANCO MUNDIAL. América Latina indígena no século XXI: a primeira década Washington, DC, 2015.

BARROS, V. E. N. Da casa de rezas à Congregação Cristã do Brasil: o pentecostalismo Guarani na Terra Indígena Laranjinha/PR. 2003. 119 f. Dissertação (Mestrado em Antropologia Social) - Universidade Federal de Santa Catarina (UFSC), Florianópolis, 2003.

O pentecostalismo entre os Guarani de Laranjinha: uma aproximação aos aspectos sociais e cosmológicos da religião tradicional. Tellus, Campo Grande, ano 4, n. 7, p. 137-146, out. 2004.

BARTOLOMÉ, Miguel Alberto. Chamanismo y religión entre los Ava-Katu-Ete. 2. ed. Assunción: Centro de Estudios Antropológicos de la Universidad Católica, 1991.

FAUSTINO, R. C. Política educacional nos anos de 1990: o multiculturalismo e a interculturalidade na educação escolar indígena. 2006. 334 f. Tese (Doutorado em Educação) - Centro de Ciências da Educação da Universidade Federal de Santa Catarina (UFSC), Florianópolis, 2006.

.Educação e religião Guarani no Paraná: estudo a partir do ritual Nimongarai. Práxis Educativa, Ponta Grossa, PR, v. 7, p. 239-263, dez. 2012. Disponível em: <http://www.revistas2.uepg.br/index.php/ praxiseducativa>. Acesso em: 30 abr. 2015.

FERNANDES, Ricardo Cid. Política e parentesco entre os Kaingang: uma análise etnológica. 2003. $303 \mathrm{f}$. Tese (Doutorado em Abtropologia Social) - Programa de Pós-Graduação em Antropologia Social da Universidade de São Paulo (USP), São Paulo, 2003.

FUNDAÇÃO SOS MATA ATLÂNTICA; INSTITUTO NACIONAL DE PESQUISAS ESPACIAIS - INPE. Atlas dos remanescentes florestais da Mata Atlântica. Período de 2008-2010. São Paulo, 2011.

INSTITUTO BRASILEIRO DE GEOGRAFIA E ESTATÍSTICA - IBGE. Os indígenas no Censo Demográfico 2010: primeiras considerações com base no quesito cor e raça. Rio de Janeiro, 2012. Disponível em: <https://ww2.ibge.gov.br/indigenas/ indigena_censo2010.pdf >. Acesso em: 12 out. 2017.

LEONTIEV, A. 0 desenvolvimento do psiquismo. Lisboa: Livros Horizonte, 1978.

NIMUENDAJÚ, C. As lendas da criação e destruição do mundo como fundamentos da religião dos Apapocúva-Guarani. Tradução de Charlotte Emmerich e Eduardo B. Viveiros de Castro. São Paulo: Hucitec, 1987.

Do passado e do presente Nimongaraí: o batismo ritual de Nimuendajú. Revista Brasileira de Linguística Antropológica, v. 2, n. 1, p. 155162, jul. 2010.

NOVAK, M. S. J. Os organismos internacionais, a educação superior para indígenas nos anos de 1990 e a experiência do Paraná: estudo das ações da universidade estadual de Maringá. 2014. 342 f. Tese (Doutorado em Educação) - Universidade Estadual de Maringá, Maringá, PR, 2014.

PARANÁ. Estratégia de participação dos povos indígenas no Projeto multissetorial para o desenvolvimento do Paraná. Curitiba, 2012. Disponível em: <http://www.planejamento.pr.gov. br/arquivos/File/EPPI_ABR_2012_Indigena.pdf>. Acesso em: 02 jan. 2016.

SCHADEN, E. Aspectos fundamentais da cultura Guarani. 3. ed. São Paulo: EDUSP, 1974.

SFORNI,M.S. deF.Aprendizagem e desenvolvimento: o papel da mediação. In: CAPELLINI, V. L. F.; MANZONI, R. (Org.). Políticas públicas, práticas pedagógicas e ensino-aprendizagem: diferentes olhares sobre o processo educacional. São Paulo: Cultura Acadêmica, 2008. Disponível em: <http:// www.diaadia.pr.gov.br/nre/ibaiti/ arquivos/File/ Sforni.pdf.>. Acesso em: 22 dez. 2011.

TASSINARI, A. Concepções indígenas de infância no Brasil. Tellus, Campo Grande, ano 7, n. 13. p. 11-25, out. 2007.

VIGOTSKI, L. S. Imaginação e criação na infância: ensaio psicológico. São Paulo: Ática, 2009.

Aprendizagem e desenvolvimento intelectual na idade escolar. In: VIGOTSKII, L. S.; LURIA, A. R.; LEONTIEV, A. N. Linguagem, desenvolvimento e aprendizagem. Tradução de Maria da Pena Villalobos. 12. ed. São Paulo: Ícone, 2012.p. 103-117.

Recebido em: 07/01/2018 Aprovado em: 10/01/2019 